\title{
A Fortunate Story of an Unusual AK-47 Bullet Trajectory: Always Keep a Smartphone in Your Pocket
}

\author{
Oscar Thabouillot, MD; $;^{1,2}$ Pierre Perrier, MD; $;^{1,2}$ Nicolas-Charles Roche, MD; ${ }^{3}$ David Agard, MD; $;^{2,4}$ \\ Olivier Barbier, MD ${ }^{4}$ Guillaume Martin, MD; ${ }^{1}$ Eric Viant, MD $;{ }^{1}$ Jean-Baptiste Leclere, MD $^{2,4}$
}

1. Emergency Department, Louis-Jacques Bégin Military Hospital, St Mandé-Paris, France

2. French Military Health Service Academy Ecole du Val de Grâce, Paris, France

3. Cardiology Department, Louis-Jacques Bégin Military Hospital, St Mandé-Paris, France

4. Orthopedic and Traumatologic Surgery, Louis-Jacques Bégin Military Hospital, St Mandé-Paris, France

Correspondence:

Oscar Thabouillot

Emergency Department

Louis-Jacques Bégin Military Hospital

St Mandé-Paris, France

E-mail: thabouillot@hotmail.com

Conflicts of interest: The opinions or assertions expressed herein are the personal views of the authors and are not to be considered as official or as reflecting the views of the French Military Health Service. The authors do not declare a conflict of interest.

Keywords: rifles; terrorism; wound ballistics

Received: January 19, 2016

Accepted: January 30, 2016

Online publication: April 18, 2016

doi:10.1017/S1049023X16000364
Abstract: This is a report of a fortunate story of an unusual AK-47 bullet trajectory which took place during the Paris (France) attack of November $13^{\text {th }}, 2015$. A young man, trying to protect his girlfriend, interfered between her and a shooter. He had been wounded in the posterior compartment of the thigh. The bullet penetrated him and, instead of exiting, rebound against his Smartphone, which was in the front pocket of his pants. Thanks to that, the missile bullet did not injure his girlfriend but ended its trajectory in the fat tissue of his thigh.

Thabouillot O, Perrier P, Roche NC, Agard D, Barbier O, Martin G, Viant E, Leclere JB. A fortunate story of an unusual AK-47 bullet trajectory: always keep a Smartphone in your pocket. Prehosp Disaster Med. 2016;31(3):343-345.

\section{Clinical Situation}

This is a report of an unusual and fortunate story from the Paris (France) attack of November $13^{\text {th }}, 2015$.

The scene took place in the Bataclan Theatre. A young couple was listening to a hard rock band in the orchestra pit. Three terrorists burst into the place, shooting into the crowd with assault rifles type AK-47 $(7.62 \times 39 \mathrm{~mm})$. The young man, 30-year-old (180 cm tall), tried bravely to protect his girlfriend, 29 -year-old $(160 \mathrm{~cm}$ tall), by intervening between a shooter and her body (Figure 1). He was hit by a bullet from a Kalashnikov rifle in the left buttock, and the couple fell to the ground.

The couple was transported to the emergency department. When they arrived, only the man was wounded. The girl was safe and she had no mark of injury.

Clinical examination showed a hemodynamically stable patient. There was one entrance hole at the external dorsal face of the buttock and one exit hole at the external front face of the thigh (Figure 2).

$\mathrm{X}$-rays were performed (Figure 3 ) and showed an absence of bone fractures, but the bullet was still in his thigh. It was surprising because the entrance and exit holes of the bullet were identified clearly.

At this moment, the patient showed doctors his Smartphone, which was in the left front pocket of his pants during the shooting (Figure 4). The main hypothesis was that the bullet penetrated his thigh and ricocheted off of his Smartphone before stopping in the medial portion of the fat tissues of the left thigh.

The patient benefited from an analgesic protocol based on Paracetamol and Codeine at the emergency department and from a primary disinfection of the wound. He also received Amoxicillin-Clavulanate. Eight hours later, once the most severe patients had been taken care of, he was brought to the operating room. Under general anesthesia, the surgeon explored the wound, cleaned it again, and practiced a debridement of contused tissues in order to avoid secondary necrosis which could lead to superinfection. The nurse put an absorbent alginate dressing on every day and a progressive good local healing was noted. It is important to note that he also benefited from psychological support. The patient could go back home six days later and his satisfactory wound healing was controlled the following week during a surgical consultation. 


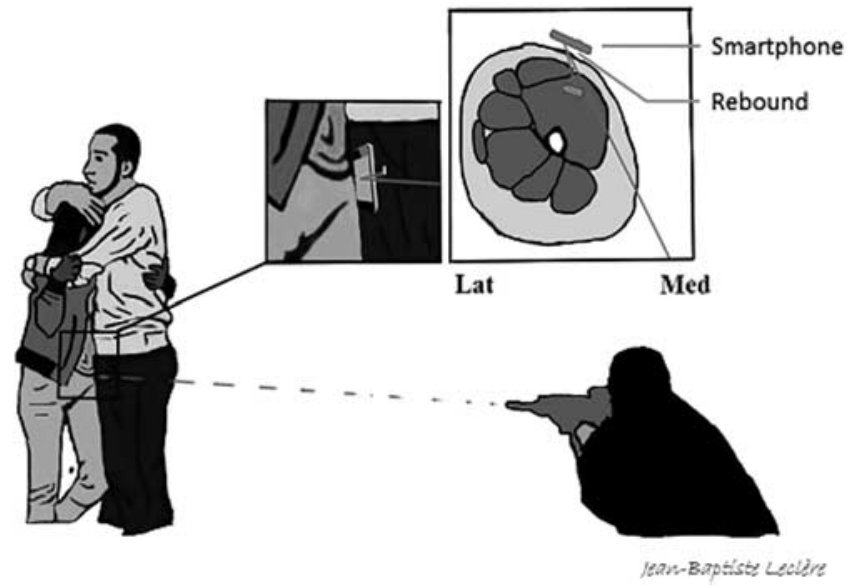

Thabouillot @ 2016 Prehospital and Disaster Medicine

Figure 1. Diagram of the Action.

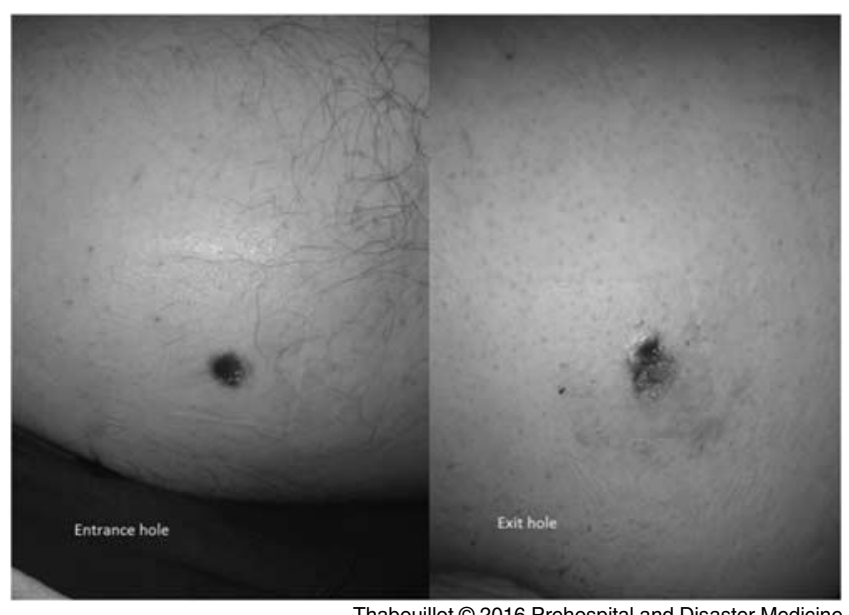

Figure 2. Entrance and Exit Holes.

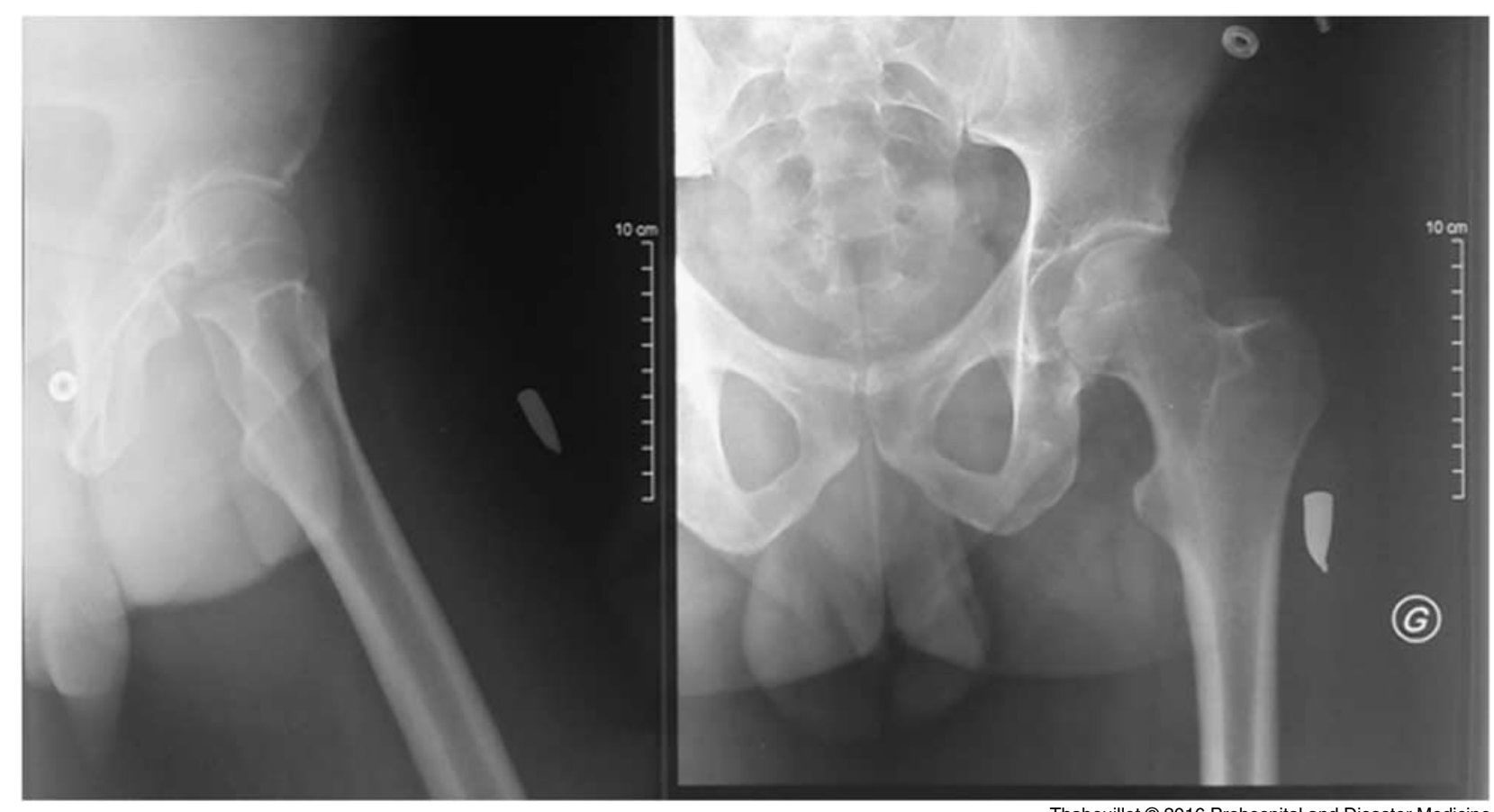

Figure 3. Left Thigh X-ray Showing AK-47 Bullet.

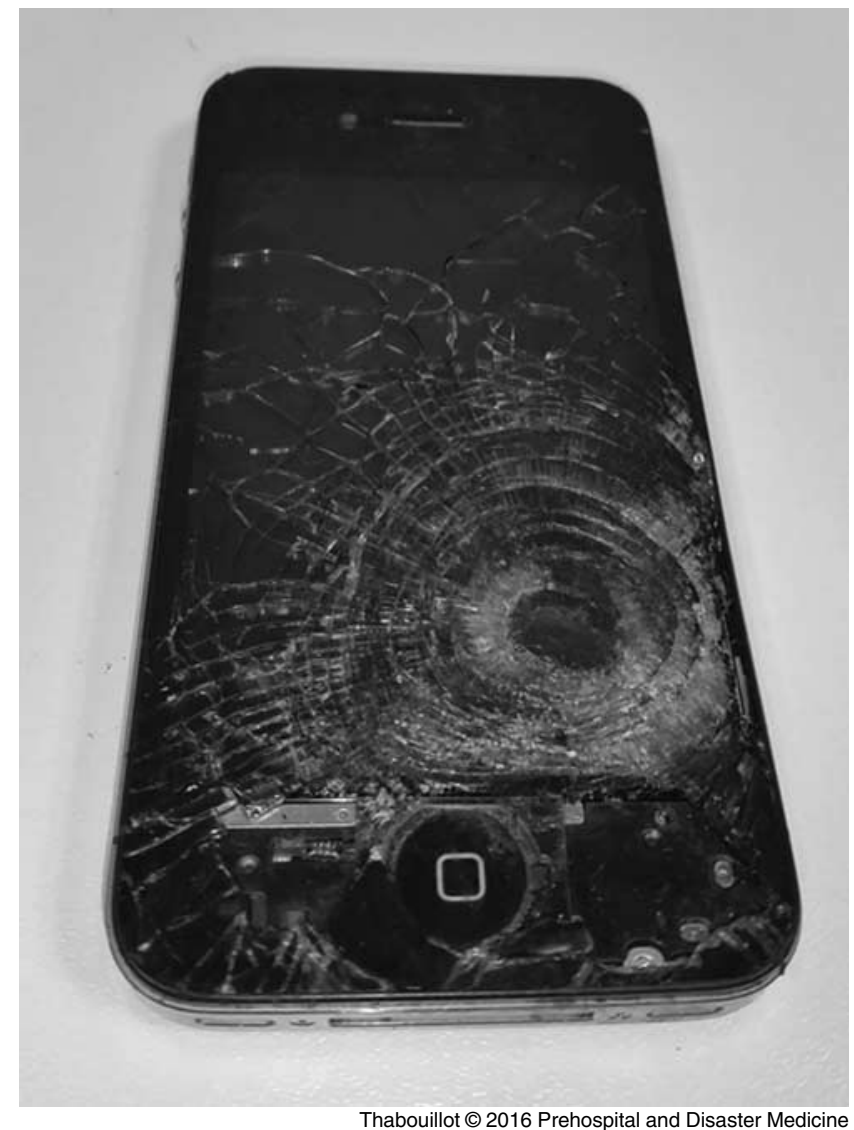

Figure 4. Smartphone with the Bullet Impact. 


\section{Discussion}

Many authors report atypical bullet trajectories. ${ }^{1-3}$ It is frequent to notice unusual courses. It is well known that bullets can rebound against bones, pivots, tip-overs, or fragments, generating severe internal injuries.

The main predictive factor of severe wounds is obviously the wound location but, when a non-vital area is wounded, it is the energy transfer and the fragmentation risk of the bullet which have to be considered. ${ }^{3}$ Bullets from Kalashnikov rifles are classified as high-velocity missiles $(>609.6 \mathrm{~m} / \mathrm{s}) .{ }^{4}$ Kinetic energy is approximately of $2250 \mathrm{~J}{ }^{4}$

AK-47 bullets are known to cause severe wounds, but they also have rectilinear trajectories, low risk of fragmentation, and low rocking movement risk. ${ }^{4}$ If the young man had not had his

References

1. Ro T, Murray R, Galvan D, Nazim MH. Atypical gunshot wound: bullet trajectory analyzed by computed tomography. Int J Surg Case Rep. 2015;14:104-107.

2. Aygün M, Tulay CM. Atypical trajectory of gunshot injury. Ulus Trauma Acil Cerrahi Derg. 2014;20(6):452-454.

3. Reginelli A, Russo A, Maresca D, Martiniello C, Cappabianca S, Brunese L. Imaging assessment of gunshot wounds. Semin Ultrasound CT MR. 2015; 36(1):57-67.

4. Dorrzapf JJ. Les projectiles des AK-47 et AK-74. EuroBalistics.
Smartphone in his pocket, it seems very probable that the bullet would have penetrated the thigh and then ended its trajectory in the abdomen or the pelvis of his girlfriend (because of the height difference between them), generating a life-threatening injury for her. In this case, it can be said that the young woman owed her life to the bravery of her boyfriend and to his Smartphone.

Nevertheless, if it can be said that the Smartphone saved the life of the patient's girlfriend, the rebound could have killed him also. If the bullet had severed an artery of the inguinal region, gravity, prognosis, and treatment would have been totally different., Indeed, a lot of military doctors and nurses know that massive bleeding due to an arterial wound can be life threatening in a few minutes. ${ }^{7}$ Moreover, the rebound could have led to a thighbone or pelvis bone fracture.

5. Ahanger AG, Wani ML, Lone RA, et al. Missile vascular injuries: 19-year experience. Ulus Travma Acil Cerrabi Derg. 2010;16(2):135-138.

6. Samokhvalov IM, Reva VA, Denisov AV, Ozeretskovskiǐ LB, Pronchenko AA. Surgical peculiarities of gunshot injuries to arteries of the extremities caused by modern small arms and light weapons. Voen Med Zh. 2014;335(10):19-24.

7. Eastridge BJ, Mabry RL, Seguin P, et al. Death on the battlefield (2001-2011): implications for the future of combat casualty care. J Trauma Acute Care Surg. 2012; 73(6 Suppl 5):S431-S437. 